\title{
Acute Phase Effect of Memantine Hydrochloride in Experimental Peripheral Nerve Injury
}

\author{
Hakan $\mathrm{AK}^{1} \quad$ Iskender Samet Daltaban ${ }^{1}$ Sevilay Vural ${ }^{2}$ \\ ${ }^{1}$ Department of Neurosurgery, Bozok University Faculty of \\ Medicine, Yozgat, Turkey \\ 2Department of Emergency, Bozok University Faculty of Medicine, \\ Yozgat, Turkey \\ Indian J Neurosurg 2019;8:113-118
}

Address for correspondence İskender Samet Daltaban, Assistant Professor, Department of Neurosurgery, Bozok University Faculty of Medicine, Yozgat, Turkey (e-mail: isamet79@hotmail.com).

\begin{abstract}
Keywords

Aim In this experimental study, we aimed to investigate possible healing effects of memantine hydrochloride, an N-methyl-d-aspartate (NMDA) antagonist, with clinical, biochemical, and histopathologic methods on acute peripheral nerve injury (PNI).

Material and Method Forty-eight adult Wistar albino rats were divided into four groups $(n=12)$. The groups were arranged as sham-operated group (group 1$)$, acute compression model group (group 2), trauma + low-dose memantine group (group 3), and trauma + high-dose memantine group (group 4). Memantine was administered intraperitoneally for 7 days. Subjects were sacrificed after the measurement of the sciatic nerve function index (SNFI) on the eighth day. Cyclooxygenase 2 (COX-2) and tumor necrosis factor- $\alpha$ (TNF- $\alpha$ ) levels were measured in nerve tissues. Histopathologic evaluation was performed by electron microscopy.

Results The mean sciatic function index (SFI) scores of groups 1 to 4 were +3.27 (standard deviation [SD] \pm 4.66$),-18.2$ (SD = \pm 11.7$),-8.5(\mathrm{SD}= \pm 7.5)$, and -2.5 $(\mathrm{SD}= \pm 9)$, respectively. The mean $\mathrm{COX}-2$ values were $0.98 \mathrm{ng} / \mathrm{mL}(\mathrm{SD}= \pm 0.51)$, $1.89 \mathrm{ng} / \mathrm{mL}(S D= \pm 0.22), 1.39 \mathrm{ng} / \mathrm{mL}(S D= \pm 0.36)$, and $1.35 \mathrm{ng} / \mathrm{mL}(S D= \pm 0.59)$, respectively. TNF- $\alpha$ values were $0.09 \mathrm{pg} / \mathrm{mL}(S D= \pm 0.23), 1 \mathrm{pg} / \mathrm{mL}(\mathrm{SD}= \pm 0.96), 0.46$ $\mathrm{pg} / \mathrm{mL}(\mathrm{SD}= \pm 0.55)$, and $0.48 \mathrm{pg} / \mathrm{mL}(\mathrm{SD}= \pm 0.78)$, respectively. Group 1 showed normal histologic findings. Group 2 showed marked edema particularly in large-diameter myelins. Myelin configurations were detected in large myelinated axons in group 3. The number of mast cells in endoneurium was high in group 4.

- peripheral nerve injury Conclusion The efficacy of memantine in the acute phase of PNI appears to be

- memantine

- cyclooxygenase-2 significant according to the SNFI and biochemical tests. However, histologic findings suggest that high doses of memantine have a negative effect on PNI.
\end{abstract}

\section{Introduction}

Peripheral nerves can be damaged due to mechanical, thermal, chemical, congenital, and pathologic reasons. When plexus and root injuries are included, peripheral nerve injury (PNI) is detected in approximately $5 \%$ of patients admitted to first-level trauma centers. ${ }^{1,2}$ The increased feasibility of microsurgical, histologic, and immunohistochemical techniques have contributed to the success rate of nerve repair in PNI. ${ }^{3}$ However, the success rate has not been reached to the

received

September 22, 2018

accepted

October 24, 2018
DoI https://doi.org/

$10.1055 / \mathrm{s}-0039-1695668$

ISSN 2277-954X. requested levels. Therefore, in various studies, researchers have attempted to demonstrate the efficacy of neurotrophic factors, steroids, hormones, some chemical substances, and low-frequency magnetic field applications on nerve regeneration to increase the success rate in PNI. ${ }^{4-7}$

Memantine (3,5-dimethyladamantane-1-amine hydrochloride) is a clinically well tolerated, competitive $\mathrm{N}$-methyld-aspartate (NMDA) receptor antagonist with low affinity. It affects glutamatergic synaptic transmission and has an agonistic effect on the dopamine $D_{2}$ receptors. ${ }^{8}$ It has a variety of clinical

(C2019 Neurological Surgeons'

License terms

Society of India 
uses, especially in Alzheimer's disease. Moreover, its efficiency has been studied in neuropathic pain and postherpetic neuralgia. ${ }^{9-12}$ However, the studies regarding motor improvement on acute neural damage are relatively few in number. ${ }^{13}$ In our experimental study, we performed an acute sciatic nerve compression model in rats and investigated the clinical, biochemical, and histopathologic effects of memantine on acute PNI.

\section{Material and Method}

This study was carried out at Experimental Animal Laboratory, Medical Faculty, Adnan Menderes University after the approval of Ethics Committee on Experimental Use of Animals of Adnan Menderes University School of Medicine (ADU-HADYEK) dated February 2, 2009 (B.30.2.ADÜ.0.06.00.00/124-HEK/2009/63).

Forty-eight Wistar albino adult female rats with a weight of $200 \pm 20 \mathrm{~g}$ were used as subjects. The rats were fed with ad libitum feeding. Animals were maintained under standardized housing conditions with 12-hour light-dark cycle. They were weighed at the beginning of the study and before the sacrification. The animals were anesthetized with intraperitoneal administration of $8 \mathrm{mg} / 100 \mathrm{~g}$ ketamine (Alfamine 10\%, Ege Vet Animal Husbandry, Bornova/İzmir) and $1 \mathrm{mg} / 100 \mathrm{~g}$ xylazine (Alfazyme 2\%, Ege Vet Animal Husbandry, Bornova/ İzmir).

The 48 rat subjects were divided into four groups $(n=12)$. The groups were arranged as sham-operated group (group 1 ), acute compression model group (group 2), trauma + lowdose memantine group (group 3), and trauma + high-dose memantine group (group 4). In group 1, the area between the sciatic nerve origin and the first branch of it were opened by blunt dissection through the femoral and gluteal muscles after a 2-cm incision on the thigh at the ventral decubitus position. After that, anatomic closure was performed. The group 2 was created by injecting the autologous blood from the tail vein $(0.2 \mathrm{~mL})$ to the sciatic nerve intraneurally, after the sciatic nerve was revealed with a similar method as in group $1 .{ }^{14}$ Group 3 was exposed to acute compression model + low-dose memantine. The subjects of group 3 were administered low-dose memantine hydrochloride (Sigma Aldrich, memantine hydrochloride > 98\% GC, M9292) ( $1 \mathrm{mg} / \mathrm{kg} /$ day) for 7 days after the sciatic nerve dissection and acute peripheral nerve compression were established. Group 4 (acute compression model + high-dose memantine group) received high-dose intraperitoneal memantine hydrochloride $(12,5 \mathrm{mg} / \mathrm{kg} /$ day $)$ for 7 days after similar sciatic nerve dissection and acute peripheral nerve compression were established. Ad libitum feeding, fresh tap water, and standardized housing conditions (temperature, $20-24^{\circ} \mathrm{C}, 12$-hour light/dark cycle light on from 7 a.m. and $60 \pm 5 \%$ humidity) were continued during the following 7 days after the surgery. Memantine was prepared and injected at the same time of each day by the same investigator.

\section{Sciatic Function Index Measurement}

Sciatic function index (SFI) is a commonly used tool for the evaluation of functional recovery of the sciatic nerve of rats in experimental studies. It relies on footprints obtained with ink and paper. On the eighth day of the experiment, first the measurements of the third toe to heel (PL), the first toe to the fifth (TS), and the second toe to the fourth (IT) were made on sham-operation group (group 1 that is represented by $\mathrm{N}$ ) and injury groups (group 2 to 4 that are represented by E). Then motor function was assessed by walking track analysis of the rats (with slope angles of 30 degrees). During the walking test, both legs of the animals were stained with inks and scored, and the SNI was calculated from the footprints. For the calculation of SNI, we used the following formula ${ }^{15}$ :

$$
\begin{gathered}
\mathrm{SFI}=-38.3 \times(\text { EPL }-\mathrm{NPL}) / \mathrm{NPL}+109.5 \times(\text { ETS }-\mathrm{NTS}) / \mathrm{NTS}+ \\
13.3 \times(\text { EIT }-\mathrm{NIT}) / \mathrm{NIT}-8.8
\end{gathered}
$$

After the SFI scores were obtained, the animals were deeply anesthetized with intraperitoneal administration of $8 \mathrm{mg} / 100 \mathrm{~g}$ ketamine and $1 \mathrm{mg} / 100 \mathrm{~g}$ xylazine. The animals were weighed again, and their weights were noted. Then, they were dissected through the first branch of the sciatic nerve origin, and neural tissue samples were obtained. Finally, the animals were sacrificed with high-dose anesthetic agent.

\section{Biochemical Method}

Protein, tumor necrosis factor- $\alpha$ (TNF- $\alpha$ ) and cyclooxygenase 2 (COX-2) levels were determined after tissue homogenization using a $1 / 20$ dilution on ice with tissue lysis buffer (kit components; $150 \mathrm{mM} \mathrm{NaCl}, 50 \mathrm{mM}$ Tris (pH:8.0), \%1 triton $\mathrm{X}-100,1 \mu \mathrm{g} / \mathrm{mL}$ leupeptin, $1 \mu \mathrm{g} / \mathrm{mL}$ aprotinin, $1 \mu \mathrm{g} / \mathrm{mL}$ pepstatin, $1 \mathrm{mM} \mathrm{PMSF}$ ) and centrifugation at 10,000 rpm for 10 minutes at $+4^{\circ} \mathrm{C}$. The in vitro gen rat enzyme-linked immunosorbent assay (ELISA) kit for the detection of TNF level and IBLAT ELISA kit for COX-2 level were used. Tissue TNF- $\alpha$ and COX-2 levels were expressed by protein per mg.

\section{Histologic Evaluation}

Sections of $1 \mu \mathrm{m}$ were taken from the sciatic nerves passed through the electron microscopic examination and evaluated histologically using toluidine and S100 staining.

\section{Statistical Analysis}

The statistical analysis of this study was performed in the SPSS 14.0 (IBM Corp.) statistical program. The paired $t$-test was used to determine the significance of differences between groups. $p<0.05$ was considered statistically significant.

\section{Results}

Prestudy and prescarification weights of all patients in this study were measured, and the difference was observed as $\pm 5 \mathrm{~g}$ and was not statistically significant for all groups.

\section{Functional Analysis}

Walking track analysis of all the patients on an oblique plane in the study were performed before sacrificing, and SFI scores were calculated (-Graph $\mathbf{1}$ ). The mean SFI scores of groups 1 to 4 were +3.27 (standard deviation [SD] \pm 4.66 ), -18.2 $(\mathrm{SD}= \pm 11.7),-8.5(\mathrm{SD}= \pm 7.5)$, and $-2.5(\mathrm{SD}= \pm 9)$, respectively. 
A statistically significant difference was found during the comparison between groups 2 and 3 with paired $t$-test $(p<0.05)$. Also, a statistically significant difference was calculated between groups 2 and 4 with paired $t$-test $(p<0.05)$, but there was a significant difference between the groups 3 and 4 , which received memantine $(p<0.05)$.

\section{Biochemical Analysis}

COX-2 levels were measured by ELISA in sciatic nerve tissue samples from the patients ( - Graph 2). The mean COX-2 values of the groups were $0.98 \mathrm{ng} / \mathrm{mL}(\mathrm{SD}= \pm 0.51), 1.89 \mathrm{ng} / \mathrm{mL}$ $(\mathrm{SD}= \pm 0.22), 1.39 \mathrm{ng} / \mathrm{mL}(\mathrm{SD}= \pm 0.36), 1.35 \mathrm{ng} / \mathrm{mL}(\mathrm{SD}= \pm 0.59)$, respectively. A statistically significant difference was found between groups 1 and 2 in the analysis with paired $t$-test $(p<0.05)$, and mean COX-2 values were statistically lower in group 1 compared with group 3 too. Also, there was a statistically significant difference between groups 2 and 3; between groups 2 and $4(p<0.05)$. However, there was no statistically significant difference between groups 1 and 4 and groups 3 and 4 due to statistical analysis with paired $t$-test $(p>0.05)$.

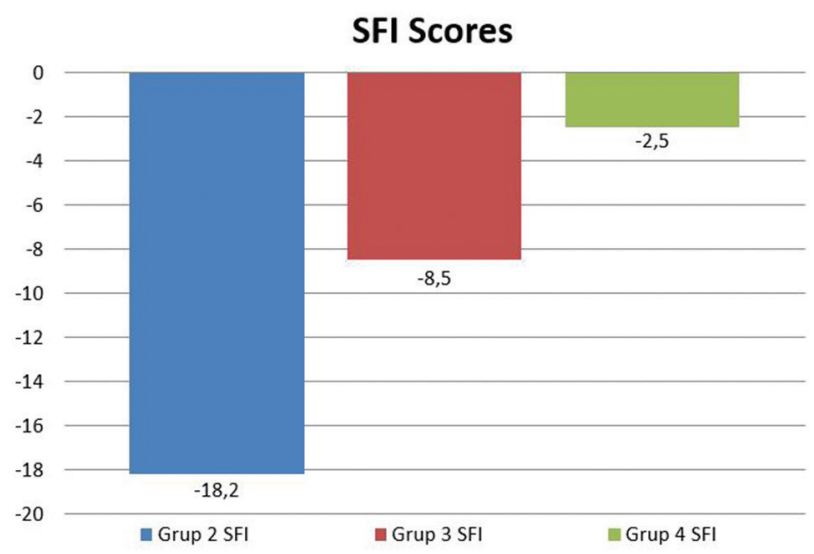

Graph. 1 Sciatic function index (SFI) scores of the groups.

\section{COX-2 Levels (ng/ml)}

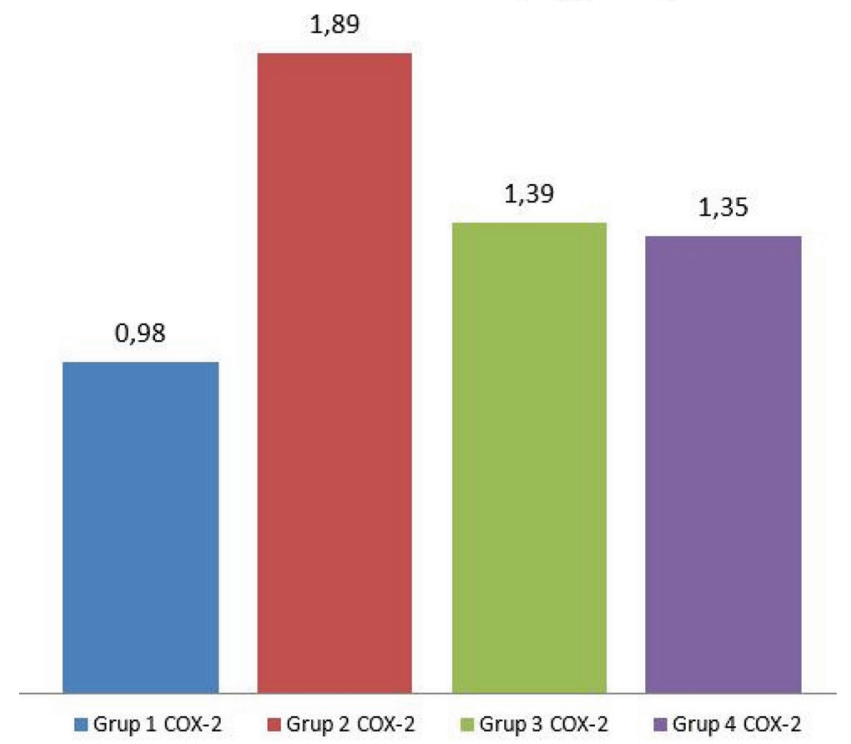

Graph. 2 COX-2 levels of the groups.

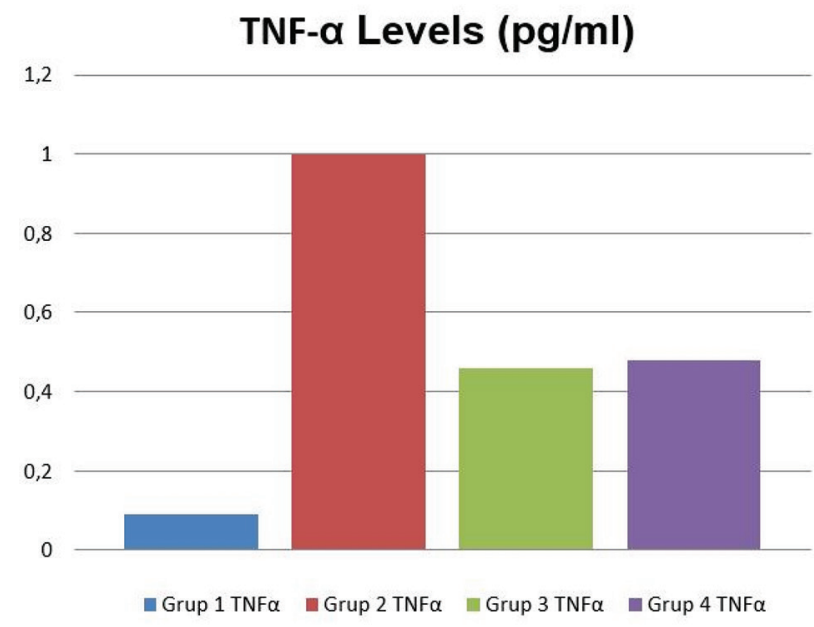

Graph. 3 TNF- $\alpha$ levels of the groups.

TNF- $\alpha$ levels were measured by ELISA in sciatic nerve tissue samples from the subjects ( - Graph $\mathbf{3}$ ). The results were $0.09 \mathrm{pg} / \mathrm{mL}(\mathrm{SD}= \pm 0.23), 1 \mathrm{pg} / \mathrm{mL}(\mathrm{SD}= \pm 0.96), 0.46 \mathrm{pg} / \mathrm{mL}$ (SD $= \pm 0.55)$, and $0.48 \mathrm{pg} / \mathrm{mL}(\mathrm{SD}= \pm 0.78)$, respectively. There was no statistical difference when group 1 was compared with groups 3 and 4 separately ( $p>0.05$ ). There was no difference between memantine received groups (groups 3 and 4).

\section{Histologic Analysis}

The sham-operated group (group 1) that was considered as control group showed normal histologic findings consisting of myelinated axons with myelin sheath thickness, surrounding structures (epi-, peri-, and endoneurium), and connective tissues in the normal ranges in slides stained with toluidine blue. Schmidt-Lanterman clefts (SLCs) in S100 thin sections studied by electron microscopy showed normal ultrastructure.

The toluidine blue-stained semi-thin sections in group 2 showed marked edema, particularly in large diameter myelins. Also, pericapillary edema and mast cells, demyelinated axons, and Schwann cell bands were detected. Myelin lamella completely disappeared in large axoplasmic areas. In S100 staining, Schmidt-Lanterman incisures (SLIs) showed significant positive reactivity in large-diameter axons at paranodal areas. Positive immunoreactivity was detected scattered between lamellae in large-diameter lamellar separated from myelins (-Fig. 1).

Myelin configurations were detected in large myelinated axons in toluidine-dyed semi-thin sections in group 3. Evacuation and disorganization were observed in axoplasmic

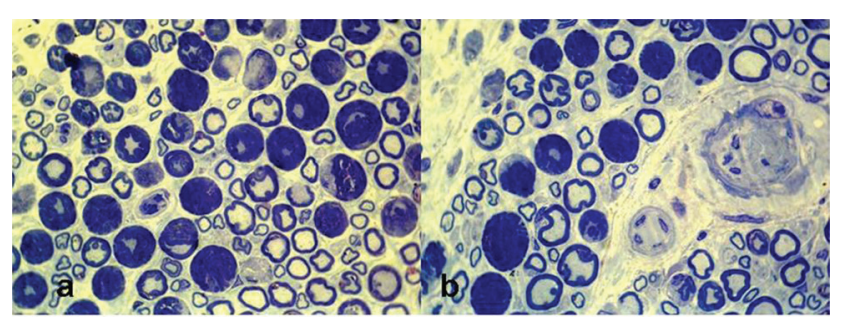

Fig. 1 Tissue samples of group 2 patients stained with toluidine blue. 


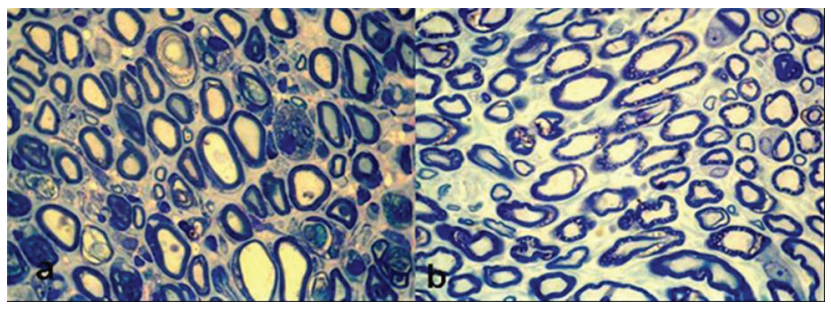

Fig. 2 Tissue samples of group 3 patients stained with toluidine blue.

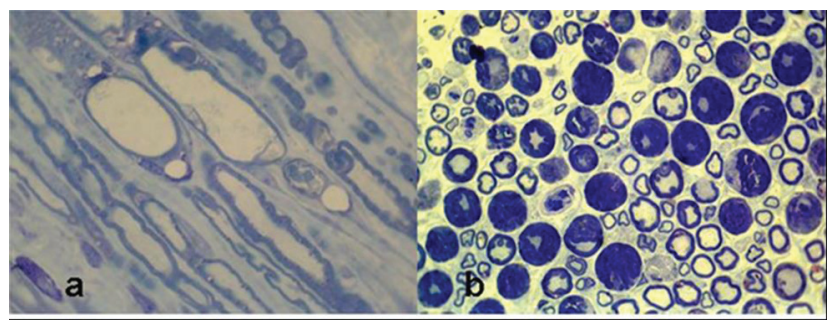

Fig. 3 Tissue samples of group 4 patients stained with toluidine blue.

areas, while occasionally proper axon structures, Schwann cell nuclei were detected in small diameter myelinated axons. Relative congestion was observed in axons between laminated myelin structures. S100 staining of the same group showed significant positive reactivity in rings of myelinated axons and large-diameter axons in the paranodal regions and SLCs (-Fig. 2).

The number of mast cells in endoneurium was high, and myelin degeneration was observed in group 4. Axoplasmic vacuole in large-diameter myelinated axons, vacuolization in Schwann cells, and mast cells among fat tissues in the epineurium region were detected. Axoplasmic myelin degradation products, axoplasmic disorganization, atrophic axons, laminal debris materials, and granular disintegration between inner myelin laminae and axons were seen. The investigation of the same group revealed predominance of large-diameter axons in paranodal regions in SLC in S100 stains. The rings of myelinated axons showed significantly positive reactivity same as Schwann cells too. However, the regularity of the myelinated rings and positive reactivity were regular and small in number ( - Fig 3 ).

\section{Discussion}

Memantine appears to be significantly effective in acute PNI considering the SFI and biochemical results of this study. However, histologic findings suggest that high doses of memantine have a negative or even deleterious effect on peripheral nerve regeneration.

Intraneural hematoma-induced nerve injuries are usually associated with trauma, bleeding disorders, or drug use such as warfarin and heparin. ${ }^{16,17}$ The surgical treatment planning for acute nerve injuries sometimes cannot be actualized in patients with hemorrhage diathesis, who use drugs that increase blood flow or in elderly patients who are not fit for surgical intervention. These patients are not good candidates for surgery, and as the time passes for the optimization, the chances of a successful surgery get lower. ${ }^{17}$ We constructed an intraneural hematoma model in our study, especially considering the patients in this group. Scopel et al aimed to compare internal neurolysis with longitudinal epineurotomy in their experimental intraneural hematoma study, in other words, to determine the number of patients who could be candidates for surgery. ${ }^{14}$ On the other hand, we focused on the contribution of low- and high-dose memantine in early healing process.

So far, various neurotrophic factors, steroids, hormones, many chemical substances, and low-frequency magnetic field applications have been studied to determine the efficiency in nerve regeneration in experimental animal and human studies. ${ }^{4-7,18}$ Experimental peripheral nerve studies were generally investigated for long-term effects (4-8 weeks). ${ }^{7,19,20} \mathrm{Howev}-$ er, we medicated the animals for 7 days and sacrificed them on the eighth day to observe the short-term effects.

Memantine is a well-tolerated, noncompetitive NMDA receptor antagonist with low affinity. It has been used in Alzheimer's disease, generalized anxiety disorder, epilepsy, opioid dependence, systemic lupus erythematosus, depression, obsessive compulsive disorder, essential tremor, Tourette's syndrome, attention deficit hyperactivity syndrome, glaucoma, tinnitus, and complex regional pain syndrome, and is also being investigated in the treatment of neuropathic pain, postherpetic neuralgia, pervasive developmental disorders, HIV-associated dementia, nystagmus, multiple sclerosis, hyperammonemia-induced encephalopathy, acute hepatic encephalopathy, and autism. ${ }^{21-28}$ Memantine studies on the peripheral nervous system have just started in recent years. These studies on experimental animals and humans in the literature are very limited in numbers and mostly directed to peripheral neuropathic pain and phantom limb pain. ${ }^{24,27,29,30}$ There is only one study aiming on the effect of memantine on recovery of motor function. ${ }^{13}$

The SFI score of the injured group without any treatment (group 2) was found to be-18.2 only. That parameter was-8.5 in the low-dose memantine group and-2.5 in the high-dose memantine group. The difference between the injured group and memantine-receiving groups, as well as between lowand high-dose memantine groups ( $p<0.05$ ), was statistically significant. According to these findings, we claim that low and high doses of memantine appear to be effective in the recovery of acute nerve injury and have a dose-dependent effect in the functional healing.

We evaluated COX-2 and TNF- $\alpha$ levels to assess the inflammatory process in sciatic nerves of the animals. After any injury to the peripheral nerves in various types, COX-2 is upregulated and prostaglandin production in macrophages and Schwann cells is increased. The studies on upregulation of COX-2 in the process of axonal regeneration have focused mostly on involvement in neuropathic pain induction rather than regeneration process. However, a strong upregulation of COX-2 after nerve injury, as well as the ability to regulate inflammatory mediators such as proinflammatory cytokines, suggests that this enzyme may also play an important role in nerve regeneration. ${ }^{38}$

We detected COX-2 level as $0.98 \mathrm{ng} / \mathrm{mL}$ in sham-operated group that indicated that COX-2 was present in uninjured sciatic nerves, and the statistically significant increase in COX-2 
that rises during acute injury could be considered as an indicator of that in group 2. COX-2 level of group 3 was measured statistically higher than group 1. However, the increment level of COX-2 in group 3 that received low-dose memantine was lower than group 2 that did not receive any medication. However, the statistical difference of groups 2 and 3 was continued to be preserved, which might be associated with less therapeutic effect of lower memantine dose. The results showing a statistical difference between groups 2 and 4 support this hypothesis. A statistical difference between groups 1 and 4 that received high-dose memantine might suggest higher level of recovery at higher doses. However, the reason why there was no statistical difference between memantine received groups (groups 3 and 4 ) was not fully understood.

TNF- $\alpha$ is a member of the cytokine group that stimulates the acute phase reaction..$^{39-42}$ It has been studied particularly on neuropathic pain extensively. ${ }^{43}$ TNF- $\alpha$ involves in wallerian degeneration and regeneration following PNI. This is demonstrated by some studies of crushing complete or incomplete sciatic nerve lesions and chronic entrapment injuries. ${ }^{44,45}$ George et al have suggested that TNF is produced during acute injury period in experimental studies. ${ }^{44}$ TNF- $\alpha$ levels in group 1 were close to zero in our study $(0.09 \mathrm{pg} / \mathrm{mL})$. This value significantly increased to $1 \mathrm{pg} / \mathrm{mL}$ in group 2 that is the pure injury group. No significant difference between the other groups (graph 3 and 4) may be attributed to the therapeutic effects of memantine. There was no significant difference between low and high doses, which may be due to the same effect. Nevertheless, as reported in the literature, TNF- $\alpha$ peaks at 12 hours and drops after the third day, which may also be associated with these results.

Schwann cells are supporting structures surrounding the axons in the peripheral nervous system and making the myelin sheath around the axon. This close relationship between Schwann cells and axons is an indication that these cells have special effects on axons. ${ }^{46}$ Disruption of axonSchwann cell association causes significant changes in axons and Schwann cells. These cellular changes occur at the end of the proximal and distal nerve segments. Morphologic changes in the distal segment begin within the first 3 days after injury. Fragments start to shrink and get an oval appearance. Macrophage migration to the injury side starts on the second day and reaches to the highest level at the fourth and seventh days. They clear axonal debris within 15 to 30 days completely. ${ }^{47}$ Schwann cells rapidly divide by mitosis to fill the space filled with axons and myelin sheath on the third day. Disorganization in the axoplasmic cell skeleton, products of lamellar and vesicular destruction debris, and atrophic axoplasmic edema were checked to see whether they changed with memantine. Neuronal damage to blunt traumas causes secondary damage by release of glutamate. Schwann cells were found to be distributed differently in S100 immunoreactivity evaluation. In myelinated fibers, the amount of S100 immunoreactivity turned out to be directly related to the thickness of the myelin sheath formed by Schwann cells. The S100 immunoreactivity in unmyelinated fibers was the same as small myelinated fibers. The histologic results of high-dose memantine have been found to have adverse effects on nerve regeneration processes.

\section{Conclusion}

Efficacy of memantine in the acute phase of PNI appears to be significant according to the SNFI and biochemical tests. However, histologic findings suggest that high doses of memantine have a negative or even deleterious effect on peripheral nerve regeneration. The data from our study are not enough to make a general statement, and further investigations with similar models are required to confirm this assumption.

\section{Conflicts of Interest}

None declared.

\section{Funding}

This study was supported by Scientific Research Projects of Adnan Menderes University with the number of TPF 10020.

\section{Acknowledgment}

Thanks are given to Mehmet TURGUT for being the thesis advisor of this study from Adnan Menderes University, Meral Baka, and Yiğit Uyanikgil from Ege University for performing histopathologic assessment, and Mukadder Serter from Adnan Menderes University for performing biochemical assessments.

\section{References}

1 Robinson LR. Traumatic injury to peripheral nerves. Muscle Nerve 2000;23(6):863-873

2 Burnett MG, Zager EL. Pathophysiology of peripheral nerve injury: a brief review. Neurosurg Focus 2004;16(5):E1

3 Frostick SP, Yin Q, Kemp GJ. Schwann cells, neurotrophic factors, and peripheral nerve regeneration. Microsurgery 1998;18(7):397-405

4 Pagnotta A, Tos P, Fornaro M, Gigante A, Geuna S, Battiston B. Neurotrophins and their receptors in early axonal regeneration along muscle-vein-combined grafts. Microsurgery 2002;22(7):300-303

5 Melcangi RC, Cavarretta IT, Ballabio M, et al. Peripheral nerves: a target for the action of neuroactive steroids. Brain Res Brain Res Rev 2005;48(2):328-338

6 Marcolino AM, Barbosa RI, Neves LMS, et al. Low intensity laser $(830 \mathrm{~nm})$ functional to recover of the sciatic nerve in rats. Acta Ortop Bras 2010;18(4):207-211

7 Morani AS, Bodhankar SL. Neuroprotective effect of vitamin E acetate in models of mononeuropathy in rats. Neuroanatomy 2008;7:33-37

8 Seeman P, Caruso C, Lasaga M. Memantine agonist action at dopamine D2 high receptors. Synapse 2008;62(2):149-153

9 Buvanendran A, Kroin JS. Early use of memantine for neuropathic pain. Anesth Analg 2008;107(4):1093-1094

10 Park BY, Park SH, Kim WM, et al. Antinociceptive effect of memantine and morphine on vincristine-induced peripheral neuropathy in rats. Korean J Pain 2010;23(3):179-185

11 Chipana C, Camarasa J, Pubill D, Escubedo E. Memantine prevents MDMA-induced neurotoxicity. Neurotoxicology 2008;29(1):179-183

12 Sang CN, Booher S, Gilron I, Parada S, Max MB. Dextromethorphan and memantine in painful diabetic neuropathy and 
postherpetic neuralgia: efficacy and dose-response trials. Anesthesiology 2002;96(5):1053-1061

13 Ghayour M-B, Abdolmaleki A, Behnam-Rassouli M. The effect of memantine on functional recovery of the sciatic nerve crush injury in rats. Turk Neurosurg 2017;27(4):641-647

14 Scopel GP, Faria JCM, Busnardo FF, Alves HRN, Orpheu SC, Ferreira MC. Experimental intraneural hematoma model in rats: evaluation of functional recovery and neural histomorphometry. Acta Ortop Bras 2007;15(4):222-226

15 Omura T, Sano M, Omura K, Hasegawa T, Nagano A. A mild acute compression induces neurapraxia in rat sciatic nerve. Int. J Neurosci 2004;114(12):1561-1572

16 Andrews FJ. Retroperitoneal haematoma after paracetamol increased anticoagulation. Emerg Med J 2002;19(1):84-85

17 Elesber AA, Kent PD, Jennings CA. Compressive neuropathy of the brachial plexus and long thoracic nerve: a rare complication of heparin anticoagulation. Chest 2001;120(1):309-311

18 Makwana M, Raivich G. Molecular mechanisms in successful peripheral regeneration. FEBS J 2005;272(11):2628-2638

19 Kalender AM, Doğan A, Bakan V, Yildiz H, Gökalp MA, Kalender M. Effect of Zofenopril on regeneration of sciatic nerve crush injury in a rat model. J Brachial Plex Peripher Nerve Inj 2009;4:6

20 Algora J, Chen L-E, Seaber AV, Wong GHW, Urbaniak JR. Functional effects of lymphotoxin on crushed peripheral nerve. Microsurgery 1996;17(3):131-135

21 Areosa Sastre A, McShane R, Sherriff F. Memantine for dementia. Cochrane Database Syst Rev 2004; ( 4):CD003154

22 Geter-Douglass B, Witkin JM. Behavioral effects and anticonvulsant efficacies of low-affinity, uncompetitive NMDA antagonists in mice. Psychopharmacology (Berl) 1999;146(3):280-289

23 Handforth A, Bordelon Y, Frucht SJ, Quesada A. A pilot efficacy and tolerability trial of memantine for essential tremor. Clin Neuropharmacol 2010;33(5):223-226

24 Buvanendran A, Kroin JS. Early use of memantine for neuropathic pain. Anesth Analg 2008;107(4):1093-1094

25 Vogels BAPM, Maas MAW, Daalhuisen J, Quack G, Chamuleau RAFM. Memantine, a noncompetitive NMDA receptor antagonist improves hyperammonemia-induced encephalopathy and acute hepatic encephalopathy in rats. Hepatology 1997;25(4):820-827

26 Harvey BH, Bothma T, Nel A, Wegener G, Stein DJ. Involvement of the NMDA receptor, NO-cyclic GMP and nuclear factor K- $\beta$ in an animal model of repeated trauma. Hum Psychopharmacol 2005;20(5):367-373

27 Park BY, Park SH, Kim WM, Yoon MH, Lee HG. Antinociceptive effect of memantine and morphine on vincristine-induced peripheral neuropathy in rats. Korean J Pain 2010;23(3):179-185

28 Chipana C, Camarasa J, Pubill D, Escubedo E. Memantine prevents MDMA-induced neurotoxicity. Neurotoxicology 2008;29(1):179-183

29 Sang CN, Booher S, Gilron I, Parada S, Max MB. Dextromethorphan and memantine in painful diabetic neuropathy and postherpetic neuralgia: efficacy and dose-response trials. Anesthesiology 2002;96(5):1053-1061

30 Schifitto G, Navia BA, Yiannoutsos CT, et al; Adult AIDS Clinical Trial Group (ACTG) 301; 700 Teams; HIV MRS Consortium. Memantine and HIV-associated cognitive impairment: a neuropsychological and proton magnetic resonance spectroscopy study. AIDS 2007;21(14):1877-1886
31 Suzuki R, Matthews EA, Dickenson AH. Comparison of the effects of MK-801, ketamine and memantine on responses of spinal dorsal horn neurones in a rat model of mononeuropathy. Pain 2001;91(1-2):101-109

32 Chen S-R, Samoriski G, Pan H-L. Antinociceptive effects of chronic administration of uncompetitive NMDA receptor antagonists in a rat model of diabetic neuropathic pain. Neuropharmacology 2009;57(2):121-126

33 Schley M, Topfner S, Wiech K, et al. Continuous brachial plexus blockade in combination with the NMDA receptor antagonist memantine prevents phantom pain in acute traumatic upper limb amputees. Eur J Pain 2007;11(3):299-308

34 Wiech K, Kiefer R-T, Töpfner S, et al. A placebo-controlled randomized crossover trial of the. $N$-methyl-D-aspartic acid receptor antagonist, memantine, in patients with chronic phantom limb pain. Anesth Analg 2004;98(2):408-413

35 Nikolajsen L, Gottrup H, Kristensen AGD, Jensen TS. Memantine (a N-methyl-D-aspartate receptor antagonist) in the treatment of neuropathic pain after amputation or surgery: a randomized, double-blinded, cross-over study. Anesth Analg 2000;91(4):960-966

36 Hackworth RJ, Tokarz KA, Fowler IM. Wallace SC, Stedje-Larsen ET. Profound pain reduction after induction of memantine treatment in two patients with severe phantom limb pain. Anesth Analg 2008;107(4):1377-1379

37 Chaplan SR, Malmberg AB, Yaksh TL. Efficacy of spinal NMDA receptor antagonism in formalin hyperalgesia and nerve injury evoked allodynia in the rat. J Pharmacol Exp Ther 1997;280(2):829-838

38 Cámara-Lemarroy CR, Guzmán-de la Garza FJ, Barrera-Oranday EA, Cabello-García AJ, García-Tamez A, Fernández-Garza NE. Celecoxib accelerates functional recovery after sciatic nerve crush in the rat. J Brachial Plex Peripher Nerve Inj 2008;3(25):25

39 Bashyam H, Cerami A. Uncovering the dark side of TNF. J Exp Med 2007;204(9):2013

40 Locksley RM, Killeen N, Lenardo MJ. The TNF and TNF receptor superfamilies: integrating mammalian biology. Cell 2001;104(4):487-501

41 Sullivan KE. TNF and TNFo inhibitors: mechanisms of action. Pediatr Rheumatol Online J 2004;2(1):7-22

42 Dayer J-M, Beutler B, Cerami A. Cachectin/tumor necrosis factor stimulates collagenase and prostaglandin E2 production by human synovial cells and dermal fibroblasts. J Exp Med 1985;162(6):2163-2168

43 Moldawer LL, Marano MA, Wei H, et al. Cachectin/tumor necrosis factor- $\alpha$ alters red blood cell kinetics and induces anemia in vivo. FASEB J 1989;3(5):1637-1643

44 George A, Schmidt C, Weishaupt A, Toyka KV, Sommer C. Serial determination of tumor necrosis factor-alpha content in rat sciatic nerve after chronic constriction injury. Exp Neurol 1999;160(1):124-132

45 La Fleur M, Underwood JL, Rappolee DA, Werb Z. Basement membrane and repair of injury to peripheral nerve: defining a potential role for macrophages, matrix metalloproteinases, and tissue inhibitor of metalloproteinases-1. J Exp Med 1996;184(6):2311-2326

46 Corfas G, Velardez MO, Ko CP, Ratner N, Peles E. Mechanisms and roles of axon-Schwann cell interactions. J Neurosci 2004;24(42):9250-9260

47 M F G, M M, S H, Khan WS. Peripheral nerve injury: principles for repair and regeneration. Open Orthop J 2014;8:199-203 